\title{
SYSTEM FOR SPACE HARDWARE VIBRATION PROTECTION IN TRANSPORTATION
}

\author{
Institute of Technical Mechanics \\ of the National Academy of Sciences of U kraine and the State Space Agency of U kraine \\ 15 Leshko-Popel St., D nipro 49005, U kraine; e-mail: office.itm@ nas.gov.ua
}

\begin{abstract}
Vibration protection systems are widely used in protecting various objects against dymamic loads. The most efficient ones are pneumatic vibration protection systems, which feature superlow natural frequencies of the protected object. This is achieved by resolving the main conflict characteristic of all mechanical vibration protection systems (systems with mechanical springing elements), namely the conflict between the carrying capacity and the springing element stiffness. Using a pneumatic springing element allows one to provide an arbitrarily small (quasi-zero) stiffness in the working portion of the static characteristic with a progressive stiffness increase in bump and rebound stroke. This paper presents a new high-efficiency vibration protection system developed based on these principles. The system is designed to protect space hardware and other heavy machinery products in railway, sea, and motor transportation. It is shown that choosing the design and the design parameters allows one to provide the required dynamic performance of the vibration protection system, which is characterized by a superlow natural frequency of the protected object (less than $0.5 \mathrm{~Hz}$ ) and the required damping coefficient. As shown by experiments and calculations, it is possible to dispense with such a sophisticated and expensive component as a hydrodynamic shock absorber, which is an indispensable part of any other vibration protection system, both with metal springing elements and with pneumatic ones. A prototype of the proposed vibration protection system was developed, made, and put through dynamic tests, which confirmed its high efficiency in damping impact and harmonic disturbances. The simple design, manufacturability, and high efficiency of the proposed vibration protection system make it possible to recommend it for use both in the transportation of space hardware by different modes of transport and in the vibration protection of other objects, including self-propelled heavy machinery
\end{abstract}

Keywords vibration protection system, natural frequency, amplitude and phase response, relaxation time, pneumatic suspension carrying capacity, transportation.

1. Air Actuators for Pneumatic Applications. Contitech Product Catalog. 142 pp.

2. Rampel J. Automobile Chassis. Suspension Components. Moscow: Mashinostroyeniye, 1987. 288 pp. (in Russian).

3. Ravkin G. O. Automobile Pneumatic Suspension. Moscow: Mashgiz, 1962. 289 pp. (in Russian).

4. Akopyan R. A. Pneumatic Cushioning of Motor Vehicles (Theory and Practice). Part 2. Lvov: Vysshaya Shkola, 1980, 208 pp. (in Russian).

5. Derbaremdiker A. D. Vehicle Shock Absorbers. Moscow: Mashinostroyeniye, 1985. 200 pp. (in Russian).

6. Pylypenko M. V. Dynamic performance of a vehicle driver seat pneumatic vibration protection system. Teh. Meh. 2009. No. 2. Pp. 11-26. (in Russian).

7. Pylypenko M. V. Development of a mathematical model of a vehicle driver seat pneumatic vibration protection system. Teh. Meh. 2009. No. 1. Pp. 56-70. (in Russian).

8. Pylypenko M. V., Paidem R. A. Pneumatic suspension characterization using statistical test results. Teh. Meh. 2005. No. 2. Pp. 147-157. (in Russian).

9. Pylypenko M. V. Technique for pneumatic suspension plunger profile determination. Teh. Meh. 2005. No. 2. Pp. 158-166. (in Russian).

10. Pylypenko M. V. Development of a mathematical model for a self-contained pneumatic suspension of a vehicle driver seat with the direct inclusion of a vibration protection module. Teh. Meh. 2008. No. 1. Pp. 38-49. 